\title{
EFEKTIVITAS PROGRAM POSITIF PARENTING DALAM MENGURANGI STRES PENGASUHAN PADA IBU MUDA
}

\author{
Triana Indrawati \\ Institut Agama Islam Negeri Pekalongan, Indonesia \\ Trianaindrawati@iainpekalongan.ac.id
}

\begin{abstract}
Knowledge of parenting is one thing that is important for all young mothers to know. This study aims to determine the description of parenting stress in young mothers and to determine the effectiveness of positiveprograms parenting. The sample in this study were 20 young mothers who were in Candi Village, Bandar District, Batang Regency who had early childhood (3-6 years). Samples were taken using purposive sampling. The measuring instrument in this research is the parenting stress scale, which amounts to 30 items. The data collection method is quasi-experimental quantitative. While the data analysis technique used is paired sample t-test. The results of the data analysis show that there is the effectiveness of a positive parenting program in reducing parenting stress in young mothers in Candi Village, Bandar District, Batang, Central Java, as evidenced by the difference between the pre-test and post-test results. The average value of the pre-test results was 85.55 , while the average value of the post-test results was 49.50 . Because the average value of the post-test results is smaller than the average value of the pre-test, it shows a decrease in parenting stress experienced by young mothers in Candi Village, Bandar District, Batang Regency. There was a decrease in the average rate of parenting stress.
\end{abstract}

Keywords: young mother; positive parenting; parenting stress

\begin{abstract}
Abstrak
Pengetahuan pengasuhan anak menjadi salah satu hal yang penting diketahui semua ibu muda. Penelitian ini bertujuan untuk mengetahui gambaran stres pengasuhan pada ibu muda dan mengetahui efektifitas program positif parenting. Sampel dalam penelitian ini adalah 20 orang ibu muda yang berada di Desa Candi Kecamatan Bandar Kabupaten Batang yang memiliki anak usia dini (3-6 tahun). Sampel diambil dengan menggunakan purposive sampling. Alat ukur dalam penelitian ini adalah skala stres pengasuhan yang berjumlah 30 aitem. Metode pengumpulan data adalah kuantitatif quasi eksperimen. Sedangkan teknik analisis data yang digunakan adalah paired sample t-test. Hasil analisis data menunjukan bahwa terdapat efektifitas program positif parenting dalam mengurangi stress pengasuhan pada ibu muda di Desa Candi Kecamatan Bandar Kabupaten Batang Jawa Tengah, yang terbukti dengan adanya perbedaan antara hasil pre test dan post test. Nilai rata-rata hasil pre test adalah 85.55 , sedangkan rata-rata nilai hasil post test yaitu sebesar 49.50 . Oleh karena nilai rata-rata hasil post test lebih kecil dari pada hasil rata-rata nilai pre test maka menunjukkan adanya penurunan stress pengasuhan yang dialami oleh ibu muda di Desa Candi Kecamatan Bandar Kabupaten Batang. Adanya penurunan rata-rata angka stress pengasuhan.
\end{abstract}

Kata Kunci: ibu muda; positif parenting; stress pengasuhan 


\section{PENDAHULUAN}

Stres merupakan gangguan mental yang dihadapi seseorang akibat adanya suatu tekanan. Stres tidak dapat dianggap sebagai permasalahan yang ringan, hal ini dapat mengganggu kesehatan yang berpengaruh pada psikologis, ekonomi, dan sosial (Maeng \& Shors, 2012; Rahmawati et al., 2019). Salah satu hal dapat menjadi sumber stres adalah praktik pengasuhan khususnya terjadi pada ibu yang berusia dewasa muda. Usia dewasa muda atau biasa disebut dewasa awal adalah masa transisi dari remaja menuju masa dewasa, dimulai pada usia 18 sampai dengan 40 tahun (Hurlock, 1991). Santrock juga mengatakan bahwa masa dewasa muda adalah masa transisi baik secara fisik, transisi kognitif, dan transisi peran sosial (Santrock, 1999). Masa transisi tersebut membuat individu mudah mengalami berbagai tekanan terlebih bagi wanita yang telah menjadi ibu. Transisi yang dialami baik dari dalam dirinya, dari keluarga, dan pada saat sekolah berlangsung pada waktu yang sama (Wulandari \& Afiatin, 2020). Praktik pengasuhan menjadi salah satu sumber stres yang dialami oleh ibu pada masa dewasa muda terlebih lagi dalam mengasuh anak pertama yang masih berusia dini. Dalam hal ini dukungan sosiallah yang diperlukan dalam penanganan stres pada ibu (Fitriani \& Nuryati, 2019).

Orang tua sebagai pendidik utama perlu mempunyai pengetahuan yang memadai disertai keterampilan dalam pengasuhan dan pendidikan anak (Sofyan, 2019). Terdapat hubungan antara parenting education dengan pendidikan keluarga menurut (Siti Nur M., 2016). Pertama, pembekalan pendidikan orang tua. Kedua, pendidikan anak dalam keluarga. Hal ini berupa: konsistensi, peraturan, hukuman, dan penghargaan. Harapannya dengan adanya parenting yang baik, kepribadian yang terbentuk pada anak baik pula (Candra, 2018).

Pengasuhan sangat erat dengan kemampuan suatu keluarga dalam memberikan perhatian, waktu dukungan untuk memenuhi kebutuhan fisik, mental, dan sosial anak-anak yang masih dalam fase pertumbuhan dan perkembangan. Brooks mengartikan bahwa pengasuhan adalah runtutan peristiwa yang menunjuk pada hubungan timbal balik yang dilakukan orangtua untuk mendorong tumbuh kembang anak (Brooks, 2001; White \& Psychologist, 2001). Proses pengasuhan adalah hubungan dua arah antara orangtua dan anak, dimana pada peristiwa timbal balik tersebut dipengaruhi oleh budaya dan intitusi sosial tempat anak dibesarkan. Pengasuhan bukanlah proses yang singkat, oleh sebab itu proses pengasuhan 
meliputi beberapa hal yaitu: 1) hubungan timbal balik antara anak, orang tua, dan masyarakat lingkungannya, 2) adaptasi kebutuhan hidup dan temperamen anak dengan orang tuanya, 3) pemenuhan tanggung jawab untuk membesarkan dan memenuhi kebutuhan anak, 4) peristiwa mendorong dan menolak keberadaan anak dan orang tua, 5) peristiwa yang mereduksi resiko dan perlindungan tehadap individu dan lingkungan sosialnya (Jones, 2001).

Self compasision berperan dalam stress pengasuhan yang dialami oleh seorang ibu (Kristiana, 2017). Dengan kehadiran seorang anak, dapat meningkatkan tingkat stres pada ibu (Sari et al., 2015). Pada ibu muda yang memiliki anak usia dini dituntut jauh lebih besar dalam menuangkan berbagai perhatian dan cinta kasih. Hal ini dikarenakan masa usia dini adalah masa golden age atau masa usia emas dimana pada masa itu merupakan masa-masa kritis pertumbuhan dan perkembangan. Pada masa tersebut anak harus diberikan stimulasi sebesarbesarnya karena akan mempengaruhi masa perkembangan selanjutnya (Santrock, 1999). Daya rekam anak pada masa golden age sangatlah luar biasa (Anggraini \& Kuswanto, 2019). Oleh sebab itu hal ini menjadi tantangan bagi para ibu yang akhirnya membuat ibu muda tertekan dalam mengasuh anak-anaknya. Data menunjukan ibu muda memiliki kemungkinan kerentanan lebih tinggi untuk terlibat dalam perilaku yang berisiko (misalnya, penggunaan narkoba) dan mengalami gejala stres, dengan tingkat sedang sampai gejala stres parah ditemukan di antara 30-60\% dari ibu muda. Ibu muda menghadapi beberapa penyesuaian besar untuk identitas mereka dan mereka sangat rentan mengalami depresi postpartum, stres dan perasaan terisolasi (Tashandra, 2018).

Kabupaten Batang merupakan salah satu Kabupaten di Provinsi Jawa Tengah yang memiliki angka pernikahan dini yang cukup tinggi. Selama 6 bulan terakhir di tahun 2020 tercatat ada 45 kasus pernikahan dini. Pernikahan dini terjadi disebabkan karena kebobolan dan juga tradisi. Kategori nikah muda yaitu dibawah umur 19 tahun. Sesuai dengan batasan usia minimal pernikahan dalam undang-undang. Calon Pengantin yang memiliki kesiapan mental yang belum cukup menyebabkan tingkat perceraian yang tinggi (Muslihun, 2020).

Salah satu tujuan dari pernikahan adalah memiliki keturunan atau anak. Keterampilan dalam hal pengasuhan merupakan hal yang wajib dimiliki oleh orang tua (Anindya \& Ika Febrian, 2017). Dengan banyaknya kasus pernikahan dini itu artinya banyak menghasilkan wanita dengan status ibu muda yang tentunya tidak luput dari banyaknya permasalahan 
khususnya stres pengasuhan. Hal ini diperkuat dari hasil wawancara awal dengan beberapa ibu muda di Desa Candi Kecamatan Bandar menunjukan bahwa mereka kerap dihinggapi stres dalam mengasuh anak. Adapun penyebabnya adalah komentar atau perbandingan antara anak satu dengan yang lain. Perbandingan terhadap anak semakin diperparah dengan adanya media sosial. Sejumlah ibu seringkali stres karena merasa dirinya tidak bisa seperti ibu lainnya dalam mengasuh anak, seperti yang dilihatnya di media sosial.

Selain itu terungkap dari hasil wawancara hal yang menyebabkan ibu muda stes adalah minimnya pengalaman yang dimiliki dalam mengasuh anak terlebih lagi ketika anaknya masih berusia dini. ibu-ibu tersebut mengeluhkan kesulitan dalam mengasuh anak-anak seperti contohnya ketika harus mengajari kedisiplinan, sopan santun dalam bersikap, ketidaksabaran ibu dalam merespon perilaku bermasalah sehingga ibu terkadang harus menjewer, memarahi dan mencubit anak. Fenoma di daerah lain menunjukan telah terjadi bunuh diri yang dilakukan oleh ibu muda di daerah Boyolali akibat stres dalam mengasuh anaknya (Septhia, 2014).

Ketika membicarakan stres pengasuhan pada ibu muda maka hal yang menjadi faktor untuk meminimalisir adalah keterampilan ibu tersebut dalam mengasuh anak. Adapun hal yang bisa meningkatkan keterampilan pengasuhan ibu muda dalam mengasuh anak sehingga dapat mengurangi tingkat stres adalah Program Positif Parenting (triple P). Triple $\mathrm{P}$ dapat meningkatkan efikasi diri orangtua , mengurangi stres pengasuhan, menciptakan kerjasama orangtua dalam pengasuhan, menurunkan pengasuhan disfungsional, mengurangi konflik dalam pengasuhan, meningkatkan keharmonisan interaksi keluarga dan mengurangi permasalahan perilaku dan emosional anak (Sanders, 2012).

Hasil wawancara yang dilakukan dengan seorang ibu muda berinisial MF di Desa Candi Kecamatan Bandar mengatakan bahwa warganya banyak sekali yang menikah dini lantaran tradisi. Anak perempuan lulus Sekolah Dasar biasanya langsung disuruh menikah. Jika tidak mau menikah, kebanyakan dari mereka memilih bekerja di Jakarta sebagai Asisten Rumah Tangga (ART). Mereka berdalih "buat apa sekolah tinggi-tinggi tapi penghasilannya sedikit, lebih baik jadi pembantu tapi penghasilannya banyak". Oleh karena faktor mindset tersebut, maka banyak warga Candi khususnya ibu-ibu muda yang hanya lulusan SD. MF mengatakan saat ini di Desa Candi juga masih minim sekali yang sekolah sampai Perguruan Tinggi. Baru ada 2 lulusan saja. 
Ketika ditanya tentang problematika yang dihadapi oleh ibu-ibu muda dalam mendidik anaknya, MF mengatakan bahwa hal yang membuat stres terhadap pengasuhan adalah minimnya pengetahuan tentang praktik pengasuhan anak, sehingga ibu-ibu tersebut sulit memperlakukan anaknya dengan baik dan benar. Mereka cenderung mengasuh sebisa mereka saja tanpa dibekali pengetahuan apapun. Terkadang ketika sedang dihinggapi lelah dan anaknya nakal ibu muda tersebut sering berbuat kasar terhadap anak seperti berteriak dan menjewer anaknya nakal tanpa tahu dampak kedepanya. Selain itu lebih lanjut ibu muda tersebut mengungkapkan bahwa sulit untuk meluapkan perasaanan stres dan emosi negatif yang dirasakan akibat mengasuh anak terhadap anggota keluarga lain hal ini dikarenakan anggota keluarga lain khususnya suami menganggap bahwa hal tersebut biasa dalam mengasuh anak hal ini pula menjadikan stres akibat pengasuhan yang dialami ibu muda semakin menjadi.

Berdasarkan fenomena-fenomena yang ada dan hasil penelitian terdahulu, maka peneliti merasa penting untuk meneliti efektifitas program positif parenting sebagai faktor yang dapat mengurangi tingkat stres pengasuhan pada ibu-ibu muda di Desa Candi Kecamatan Bandar Kabupaten Batang.

\section{Stres Pengasuhan}

Stres pengasuhan adalah suatu peristiwa yang membawa pada kondisi psikologis tidak disukai dan reaksi psikologis orang tua. Stres pengasuhan dapat dimaknai sebagai suatu kondisi yang penuh dengan tekanan yang terjadi pada pelaksanaan tugas dalam mengasuh dan mengoptimalkan tumbuh kembang anak (Lestari, 2012).

Stres pengasuhan digambarkan pada situasi yang penuh dengan ketegangan dan kecemasan yang melampui batas kemampuan yang secara khusus berhubungan dengan peran sebagai orang tua dan interkasi antara orang tua dengan anak. Stres Pengasuhan mengarah pada ketidakberfungsinya peran orang tua dalam mengasuh anak. Stres pengasuhan timbul akibat ketidak seimbangan antara tuntutan yang dirasakan orangtua dengan kemampuan orang tua pada saat mengasuh anak. Selain hal tersebut kurangnya orang tua dalam memahami gangguan yang terjadi pada diri anak (Rahayu et al., 2019).

Ada tiga aspek dalam stres pengasuhan, yaitu: (1) Pengalaman stres orang tua; (2) Perilaku anak yang sulit diatur; (3) Ketidakberfungsian hubungan timbal balik antara anak dan orangtua. Sedangkan faktor yang menyebabkan stres pengasuhan diantaranya: Pertama faktor 
individu meliputi: kesehatan fisik dan mental orang tua yang kurang baik dan kondisi anak yang sulit untuk diatur contohnya suka membangkang dan tidak menghiraukan aturan yang sudah diberikan oleh orang tua. Kedua faktor keluarga meliputi: Jumlah anggota keluarga (semakin banyak anggota keluarga maka prosentase perhatian kepada masing-masing anak berkurang), masalah keuangan orangtua yang tidak bisa mencukupi kebutuhan dan keinginan anak, tekanan dari keluarga, masa lalu keluarga yang kurang baik yang dimiliki oleh orang tua, hubungan antar keluarga yang kurang harmonis. Ketiga Faktor lingkungan antara lain: status sosial ekonomi. budaya/tradisi, stres kehidupan dan kurangnya dukungan sosial.

Dalam menghadapi stres pengasuhan ada dua strategi yaitu: problem and emotion focused coping (fokus kepada problem dan emosi) dan approach vs avoident coping (fokus untuk mendekati atau menghindari problem). Strategi pertama yaitu mengubah pengalaman emosi terhadap stress. Strategi ini bertujuan untuk menghilangkan sumber stress dan mengubah dampak yang ditimbulkan oleh sumber tersebut. Sedangkan strategi kedua yaitu mendekati stress dengan cara merencanakan tindakan sebagai salah satu usaha untuk meminimalisir dampak stress yang timbul. Sebaliknya menghindari stress dilakukan dengan cara memberikan stimulasi sangkalan dalam fikiran secara kognitif (Lestari, 2012).

Ada dua pendekatan dalam menghadapi parenting stress dilihat dari sudut pandang penyebab dan akibat stress, pertama: Teori P-C-R (parent-child-relationship)yaitu munculnya stress pengasuhan yang bersumber dari orang tua, dari anak, dan dari hubungan keduanya. Kedua Teori daily hassles yaitu munculnya stress pengasuhan dipandang hal yang biasa yang dialami oleh sebagian besar orang tua dalam kehidupan sehari-hari dan tidak memiliki dampak yang terlalu signifikan.

\section{Program Positif Parenting}

Program Pengasuhan Positif atau biasa disingkat dengan Triple $P$ adalah suatu program yang dibuat dengan sistem pengasuhan dan dukungan keluarga yang dirancang oleh (Sanders, 2012). Program pengasuhan positif dimaksudkan agar orangtua memiliki kapabilitas dan keterampilan untuk mengawasi tumbuh kembang serta dapat menyelesaikan permasalahan khususnya masalah perilaku yang terjadi pada anak-anaknya (Sanders, 2012). Parenting meningkatkan hubungan antara anak dengan orang tua (Dwi et al., 2018). Dengan bekal kemampuan tersebut ibu muda dapat mengurangi terjadinya stres pengasuhan. Triple $P$ 
memiliki tujuan untuk mencegah dan mengurangi faktor resiko penganiayaan pada anak. Pengasuhan positif akan berpengaruh pada masa depan si anak itu sendiri (Resiana, 2017)

Ada lima prinsip dalam Triple-p yaitu: (1) menciptakan lingkungan yang aman dan nyaman untuk anak bereksplorasi; (2) menciptakan lingkungan belajar yang positif; (3) menggunakan pilihan disiplin asertif, (4) memiliki harapan yang real pada anak, (5) memberikan pelajaran pengasuhan yang positif sebagai orang tua. Program Positif Parenting memiliki banyak manfaat baik kepada orang tua maupun kepada anak. Diantaranya: (1) orang tua dalam mengasuh anak akan merasa lebih senang, nyaman, lega, rileks dan tenang, (2) anak akan lebih mudah untuk mengubah sikapnya ketika mereka paham bahwa apa yang dilakukannya adalah keliru, (3) anak mudah menerima nasihat dari orang tua, (4) anak belajar mengendalikan emosi yang dimilikinya, (5) anak akan memiliki sikap terbuka kepada orang tua, (6) anak lebih memiliki percaya diri yang bagus, (7) anak akan selalu nyaman dan senang bersama dengan orangtuanya.

Beberapa penelitian terkait parenting juga dilakukan beberapa peneliti, seperti hasil penelitian berikut terkait parenting menyimpulkan bahwa pada orang tua remaja tentang pengaruh program pengasuhan positif dalam meningkatkan keterampilan mindful parenting. Kualitas pengasuhan juga dipengaruhi oleh pola asuh yang positif. Semakin banyak ilmu dan pengalaman maka semakin mudah orang tua dalam mengasuh anak (Pajar Mubarok, 2016). Harus adanya keseimbangan antara pengasuhan di sekolah dan rumah serta mengawasi anak bergaul dengan temannya (Purnamasari, 2019). Program parenting memberikan pengetahuan dalam memprioritaskan pengasuhan, pembiasaan,serta mengidentifikasi tingkat kecanduan gadget (Wiyani, 2019). Perkembangan yang di miliki anak usia dini dapat di Stimulasi dan ditingkatkan melalui pemahaman parenting (Yeni Lestari, 2019). Pentingnya pemahaman parenting perlu diberikan sejak ibu dalam usia muda, karena dari beberapa penelitian terkait parenting ternyata memberikan edukasi yang sangat bermanfaat bagi perkemabangan anak usia dini.

Positif Parenting memiliki enam pilar yaitu: pertama kerja sama atau kemitraan antara ayah dan ibu (partnership parenting). Kedua bicaralah, belailah, berpikir, dan bermain disingkat menjadi 4B. ketiga kesepakatan antara orang tua dalam mendisiplinkan anak. Keempat Emosi anak harus dipahami oleh orang tua sejak dini. Kelima Gunakan bahasa yang 
santun atau bahasa yang positif dalam mendidik anak. Hindari kata “jangan”, ubah dengan katakata positif sebagai solusi terhadap larangan. Keenam Terapkan pola asuh kepada anak tanpa hukuman fisik. Maka tujuan penelitian ini adakah efektifitas program positif parenting dalam mengurangi stres pengasuhan pada ibu muda di Desa Candi Kecamatan Bandar Kabupaten Batang.

\section{METODE PENELITIAN}

Populasi dan Sampel Penelitian

Subyek dalam penelitian ini adalah ibu-ibu di fase dewasa awal dengan rentang usia 19-25 tahun di Desa Candi Kecamatan Bandar Kabupaten Batang. Ibu-ibu tersebut baru memiliki anak pertama dengan kategori anak usia dini (3-6 tahun). Jenjang pendidikan ibu kategori lulusan SD-SMA. Sampel dalam penelitian ini sebanyak 20 orang. Pengambilan sampel dilakukan dengan menggunakan teknik purposive sampling.

Pengukuran

Metode pengumpulan data yang digunakan dalam penelitian ini adalah metode kuantitatif yaitu quasi eksperimen. Metode eksperimen merupakan sebuah metode untuk menguji hipotesis yang berbentuk sebab akibat melalui sebuah treatment. Kemudian mengukur seberapa besar perubahan dari variabel bebas sebelum dan sesudah adanya treatment. Adapun untuk mengukur tingkat stres pengasuhan pada ibu muda di Desa Candi Kecamatan Bandar Kabupaten Batang, peneliti menggunakan instrument skala stres pengasuhan yang terdiri dari 30 item pernyataan.

Peneliti menggunakan desain penelitian One Group Pretest-Posttest Design yaitu peneliti melakukan satu kali pengukuran di awal (Pretest) kemudian diberikan perlakuan (Treatment) dan setelah itu diberikan pengukuran lagi (Posttest) di dalam satu kelompok saja. Treatment yang akan diberikan adalah Program Positif Parenting (triple P).

Gambar 1

the One Group Pretest and Posttest Design

\section{$\mathrm{O}_{1} \quad \mathrm{X} \quad \mathrm{O}_{2}$}


Keterangan:

$\mathrm{O}_{1}=$ Nilai pretest responden sebelum treatment

$\mathrm{X}=$ Treatment

$\mathrm{O}_{2}=$ Nilai post test responden setelah treatment

Teknik Analisis Data

Teknik analisis data yang digunakan dalam penelitian ini adalah adalah korelasi product moment pearson dan paired sample t-test. Sebelum dilakukan uji hipotesis, terlebih dahulu dilakukan uji asumsi yang meliputi: uji normalitas sebaran, uji liniearitas hubungan dan uji homogenitas. Uji hipotesis dilakukan dengan bantuan program SPSS (Statistic Package for Social Saince) 17.0 for Windows

\section{HASIL PENELITIAN DAN PEMBAHASAN}

Penelitian ini bertujuan untuk menguji efektivitas program positif parenting dalam mengurangi stres pada ibu muda. Berdasarkan hasil analisis yang telah dilakukan, hipotesis yang diajukan dapat terbukti kebenaranya yaitu terdapat efektifitas program positif parenting dalam mengurangi stress pengasuhan pada ibu muda di Desa Candi Kecamatan Bandar Kabupaten Batang. Hal ini dibuktikan dengan perbedaan hasil nilai pretest dan nilai posttest yang dilakukan oleh 20 orang responden.

Hasil posttest seluruh responden mengalami penurunan rata-rata nilai stress pengasuhan. Untuk nilai pretest diperoleh rata-rata nilai stress pengasuhan sebesar 85.55. Sedangkan untuk rata-rata nilai stres pengasuhan posttest sebesar 49.50. Oleh karena nilai ratarata stres pengasuhan pada pre test $85.55>$ post test 49.50, maka artinya secara deskriptif ada perbedaan rata-rata stress pengasuhan antara pretest dan posttest. Dengan demikian terdapat penurunan tingkat stress pada saat posttest setelah diberikan treatment yaitu workshop positif parenting kepada ibu-ibu muda di Desa Candi Kecamatan Bandar Kabupaten Batang.

Kemudian untuk menguji hipotesis, peneliti melanjutkan untuk mencari nilai perbedaan rata-rata dari hasil pre test dan post test menggunakan uji paired sampel t-test. 


\section{Tabel 1}

\section{Output Paired Sampel T-test}

\begin{tabular}{|c|c|c|c|c|c|c|c|c|}
\hline & \multicolumn{5}{|c|}{ Paired Differences } & \multirow[t]{5}{*}{$t$} & \multirow[t]{5}{*}{$d f$} & \multirow{5}{*}{$\begin{array}{c}\text { Sig. } \\
(2- \\
\text { taile } \\
\text { d) }\end{array}$} \\
\hline & \multirow[t]{4}{*}{ Mean } & \multirow{4}{*}{$\begin{array}{c}\text { Std. } \\
\text { Devia } \\
\text { tion }\end{array}$} & \multirow{4}{*}{$\begin{array}{c}\text { Std. } \\
\text { Error } \\
\text { Mean }\end{array}$} & $95 \%$ & Confidence & & & \\
\hline & & & & Interval & of the & & & \\
\hline & & & & Differenc & & & & \\
\hline & & & & Lower & Upper & & & \\
\hline Stres & 36.0500 & 8.350 & 1.8672 & 32.141 & 39.958 & 19. & 19 & .000 \\
\hline prestest & 0 & 70 & 7 & 75 & 25 & 306 & & \\
\hline and post & & & & & & & & \\
\hline tes & & & & & & & & \\
\hline
\end{tabular}

Berdasarkan hasil uji pada tabel output paired samples $t$-test, diketahui nilai sig. (2 tailed) adalah sebesar $0.000<0.05$ maka artinya hipotesis diterima. Hal ini sesuai dengan pedoman pengambilan keputusan dalam uji paired sample t-test berdasarkan nilai signifikansi (sig.) sebagai berikut (Singgih Santoso, 2014):

1. Jika nilai sig. (2-tailed) $<0.05$ maka H0 ditolak dan Ha diterima

2. Jika nilai sig. (2-tailed) $>0.05$ maka H0 diterima dan Ha ditolak

Dengan demikian dapat disimpulkan bahwa ada perbedaan rata-rata antara stress pengasuhan pretest dan posttest yang artinya ada efektifitas penggunaan program positif parenting terhadap penurunan stress pengasuhan pada ibu muda di Desa Candi Kecamatan Bandar Kabupaten Batang.

Selanjutnya dari tabel output paired samples $t$-test, juga diketahui nilai mean difference antara pretest dan posttest yaitu sebesar 36.05. Nilai mean difference diperoleh dari nilai mean pretest dikurangi nilai mean posttest $(85.55-45.50=36.05)$. Nilai ini menunjukkan selisih antara rata-rata hasil pretest dengan hasil posttest. Selisih perbedaan tersebut adalah antara 32.14 sampai dengan 39.95 (yang merupakan 95\% Confidence Interval of the Difference lower upper).

Program positif parenting sangat dibutuhkan oleh semua orang tua terutama ibu-ibu muda yang notabene masih sedikit pengalaman dalam mendidik balita. Selain orang tua, program positif parenting juga dibutuhkan oleh guru-guru paud dalam mendidik siswanya di 
sekolah agar bisa mencetak generasi yang sholih-sholihah (Musthafa, 2016). Menjadi orang tua sekaligus guru tidaklah mudah. Untuk mengahadapi permasalahan dalam mengasuh anak maka dibutuhkan sebuah ilmu dalam mendidik anak.

Pendidikan adalah sebuah seni dan ilmu. Konsep pembangunan karakter mulia dalam diri anak harus dilakukan dengan cara yang positif. Kekerasan bukanlah jalan yang terbaik dalam mendidik anak. Hal ini justru membuat anak meniru perilaku kekerasan sebagai bentuk apa yang telah ia lihat dan rasakan. Tapi sebaliknya jika anak selalu di perlakukan dengan baik (perlakuan baik bukan berarti manja) maka anak akan meniru hal tersebut. Karena anak memiliki daya imitasi daya tiru yang sangat tinggi terlebih pada masa golden age. Orang tua hendaknya memahami psikologi anak. Orang tua sebagai guru dan sahabat untuk anaknya hendaknya mendidik anak dengan cinta. Warisan paling baik bagi anak adalah kesantunan dan kelembutan yang sudah ditanamkan dan dicontohkan oleh orang tua pada masa kecil (Hassan, 2011). Ada 6 langkah edukatif dalam mewujudkan ketenangan ketika mengasuh anak, sehingga tidak muncul emosi dan akhirnya menimbulkan stress berlebih. Adapun 6 langkah tersebut adalah sebagai berikut:

1. Mendidik dengan kasih sayang dan lemah lembut

2. Jauhi sikap kasar, kata-kata yang kurang sopan, dan selalu memarahi anak

3. Cari cara agar anak selalu merasa senang dan gembari.

4. Hindari selalu mengekang keinginan anak, tetapi arahkan anak agar selalu melakukan halhal yang positif

5. Selalu perhatikan anak dan tanyakan apa yang ia rasakan

6. Berikan perhatian yang khusus bagi anak yang berkebutuhan khusus (Musthafa, 2016)

Keenam langkah edukatif diatas sejalan dengan program positif parenting yang memiliki lima prinsip yaitu:

1. Menciptakan lingkungan yang aman dan nyaman untuk anak bereksplorasi. Dengan adanya lingkungan yang aman, nyaman, dan menyenangkan akan semakin memudahkan anak untuk belajar sambil bermain.

2. Menciptakan lingkungan belajar yang positif. Lingkungan keluarga memiliki peranan yang sangat penting dalam mencetak karakter anak terutama di masa pandemi covid-19 pada 
tahun 2020 saat ini. Lingkungan belajar yang positif diciptakan dengan pola asuh yang positif penuh dengan cinta kasih.

3. Menggunakan pilihan disiplin asertif tanpa kekerasan. Mendisiplinkan anak adalah mengajari anak sesuai dengan aturan yang berlaku. Kenapa ada hal-hal yang dilarang dan diperbolehkan harus dijelaskan apa manfaat dan madharat-nya, sehingga anak bisa memahami dan menjalankan aturan yang sudah dibuat oleh orang tua dan juga sudah disepakati bersama dengan anak.

4. Memiliki harapan yang real terhadap anak. Hal-hal yang diinginkan oleh anak harus diperhatikan oleh orang tua. Bagaimana orang tua mampu mengarahkan keinginan anak sesuai dengan bakat dan minat yang dimiliki.

5. Memiliki bekal dan kemampuan mendidik positif kepada anak merupakan hal yang wajib dimiliki oleh orang tua. Anak bukanlah kelinci percobaan. Akan tetapi anak adalah anugrah dari Tuhan yang harus kita asuh dengan baik. Oleh karena itu, mendidik anak harus dengan ilmu. Pengetahuan orang tua terkait pola asuh anak harus dimiliki.

Setelah diadakannya treatment yang berupa workshop positif parenting kepada ibu-ibu muda di Desa Candi Kecamatan Bandar Kabupaten Batang, diperoleh hasil perubahan tingkat stress pengasuhan. Ada penurunan tingkat stress pengasuhan yang dibuktikan dengan adanya selisih mean difference dari hasil nilai pre test dan post test sebesar 36.05 dengan standar deviasi 8.35 .

Dilihat dari subyek penelitian yaitu ibu-ibu muda di Desa Candi Kecamatan Bandar Kabupaten Batang yang masih kurang pengalaman dalam mendidik anak, terlebih lagi rata-rata banyak yang lulusan Sekolah Dasar (SD) maka peneliti memandang bahwa treatment program positif parenting merupakan faktor yang sangat penting dalam rangka meningkatkan kualitas pola asuh dan menurunkan tingkat stres pengasuhan. Semakin banyak ilmu dan pengetahuan, maka semakin banyak bekal untuk mengasuh anak secara baik. Dengan memberlakukan pola asuh yang baik, maka otomatis stres pengasuhan juga bisa dikendalikan.

\section{SIMPULAN DAN SARAN}

Berdasarkan hasil analisis dan pembahasan maka dapat disimpulkan bahwa terdapat efektifitas program positif parenting dalam mengurangi stres pengasuhan pada ibu muda di 
Desa Candi Kecamatan Bandar Kabupaten Batang yang terbukti dengan adanya perbedaan antara rata-rata hasil pretest dan posttest. Nilai rata-rata hasil pretest adalah 85.55 , sedangkan rata-rata nilai hasil posttest yaitu sebesar 49.50. Oleh karena nilai rata-rata hasil posttest lebih kecil dari pada hasil rata-rata nilai pretest maka menunjukkan adanya penurunan stress pengasuhan yang dialami oleh ibu muda di Desa Candi Kecamatan Bandar Kabupaten Batang. Adanya penurunan rata-rata angka stress pengasuhan adalah sebesar mean difference yaitu 36.05 dengan standar deviasi 8.35.

Saran yang dapat peneliti berikan mengenai efektifitas program positif parenting dalam menurunkan stress pengasuhan pada ibu muda berdasarkan hasil penelitian ini adalah: bagi orang tua, hasil penelitian ini harap bisa digunakan sebagai dasar untuk menerapkan pola asuh yang positif bagi anak. Mindset yang selama ini tertanam bahwa anak itu sulit diatur, nakal, dan lain sebagainya harus dirubah. Bagi guru paud, hasil penelitian ini bisa digunakan sebagai pijakan dalam memberikan pembelajaran yang selalu mengacu pada prinsip-prinsip positif parenting. Bagi peneliti selanjutnya, peneliti menyarankan untuk menambah dan mengkombinasikan dengan variabel yang lainnya seperti religious parenting, supaya penelitian selanjutnya bisa lebih kompleks dan komplit.

\section{DAFTAR PUSTAKA}

Anggraini, W., \& Kuswanto, C. W. (2019). Teknik Ceklist Sebagai Asesmen Perkembangan Sosial Emosional di RA. Al-Athfaal: Jurnal Ilmiah Pendidikan Anak Usia Dini, 2(2), 61-70. https://doi.org/10.24042/ajipaud.v2i2.5248

Anindya, I., \& Ika Febrian, K. (2017). Hubungan Antara Regulasi Emosi Dengan Stres Pengasuhan Ibu Yang Memiliki Anak Cerebral Palsy. Empati, 6(4), 323-328.

Brooks, B. J. (2001). Parenting. 3rd Edition. Mayfield Publishing Company.

Candra, S. (2018). Pelaksanaan Parenting Bagi Orang Tua Sibuk dan Pengaruhnya Bagi Perkembangan Anak Usia Dini. ThufuLA: Jurnal Inovasi Pendidikan Guru Raudhatul Athfal, 5(2), 267. https://doi.org/10.21043/thufula.v5i2.3475

Dwi, W. N. P., Sri, W., \& Widianto, E. (2018). Parenting Day Sebagai Aktivitas Peningkatan Hubungan Orangtua Dan Anak. Jurnal Pendidikan Nonformal, 3(1).

Fitriani, A., \& Nuryati, I. (2019). Dukungan Sosial dan Tingkat Stres pada Ibu Pasca Melahirkan Anak Pertama. Jurnal Psikologi Malahayati, 1(2). https://doi.org/10.33024/jpm.v1i2.1856

Hassan, S. B. (2011). Mendidik Anak Zaman Kita. Zaman.

Hurlock, E. B. (1991). Psikologi Perkembangan Suatu Pendekatan Sepanjang Rentang Kehidupan.(Terjemahan: Istiwijayanti dan Soedjarwo). Erlangga.

Jones, D. (2001). Parenting Education and Support. Child: Care, Health and Development, 
27(5), 463-464. https://doi.org/10.1046/j.1365-2214.2001.0210a.x

Kristiana, A. I. I. F. (2017). Self-Compassiondan Stres Pengasuhan Ibu Yang Memiliki Anak Dengan Hambatan Kognitif. Jurnal Ecopsy, 4(1), 52.

https://doi.org/10.20527/ecopsy.v4i1.3415

Lestari, S. (2012). Psikologi Keluarga. Kencana.

Maeng, L. Y., \& Shors, T. J. (2012). Once a mother, always a mother: Maternal experience protects females from the negative effects of stress on learning. Behavioral Neuroscience, 126(1), 137-141. https://doi.org/10.1037/a0026707

Muslihun. (2020). 45 Pernikahan Dini Terjadi di Batang, Disebabkan "Kebobolan" dan Tradisi. Ayosemarang.Com.

Musthafa, A. S. (2016). Positive Parenting. Kiswah Media.

Pajar Mubarok, P. (2016). Program Pengasuhan Positif untuk Meningkatkan Keterampilan Mindful Parenting Orangtua Remaja. Psympathic : Jurnal Ilmiah Psikologi, 3(1), 35-50. https://doi.org/10.15575/psy.v3i1.1095

Purnamasari, F. B. (2019). Hubungan antara guru dan orang tua melalui program parenting perkembangan anak. Jurnal Pendidikan Luar Sekolah, 13(1), 11. https://doi.org/10.32832/jpls.v13i1.2775

Rahayu, A. T. D., Ni'matuzahroh, N., \& Amalia, S. (2019). Religiusitas dan stres pengasuhan pada ibu dengan anak autis. Jurnal Ilmiah Psikologi Terapan, 7(2). https://doi.org/10.22219/jipt.v7i2.8282

Rahmawati, M. N., Rohaedi, S., \& Sumartini, S. (2019). Tingkat Stres Dan Indikator Stres Pada Remaja Yang Melakukan Pernikahan Dini. Jurnal Pendidikan Keperawatan Indonesia, 5(1). https://doi.org/10.17509/jpki.v5i1.11180

Resiana, N. (2017). Implementasi Program Parenting Dalam Menumbuhkan Perilaku Pengasuhan Positif Orang Tua Di Paud Tulip Tarogong Kaler Garut. Jurnal Pendidikan Luar Sekolah, 13(2), 31-41.

Sanders, M. R. (2012). Development, Evaluation, and Multinational Dissemination of the Triple P-Positive Parenting Program. Annual Review of Clinical Psychology, 8(1), 345379. https://doi.org/10.1146/annurev-clinpsy-032511-143104

Santrock, J. W. (1999). Psikologi Perkembangan . (Terjemahan : B. Adelar dan S. Sharagih). Erlangga.

Sari, D. Y., Pranaji, D. K., \& Yuliati, L. N. (2015). Stres Ibu dalam Mengasuh Anak pada Keluarga dengan Anak Pertama Berusia di Bawah Dua Tahun. Jurnal Ilmu Keluarga Dan Konsumen, 8(2), 80-87. https://doi.org/10.24156/jikk.2015.8.2.80

Septhia, R. (2014). Kasus Bunuh Diri Boyolali : Diduga Depresi, Ibu Muda Nyemplung Sumur. Https://Www.Solopos. Com/.

Siti Nur M. (2016). Parenting Education Sebagai Pendidikan Keluarga (Motiv Keterlibatan Orang Tua Dalam Parenting Education). Jurnal Paradigma, 4(1-10).

Sofyan, I. (2019). Mindful Parenting: Strategi Membangun Pengasuhan Positif dalam Keluarga. Journal of Early Childhood Care and Education, 1(2), 41. https://doi.org/10.26555/jecce.v1i2.241

Tashandra, N. (2018). Stres Ibu Juga Pengaruhi Psikologis Anak. Www.Kompas.Com. White, C., \& Psychologist, C. (2001). Parenting Matters: What Works in Parenting Education? Child: Care, Health and Development, 27(4), 379-379. https://doi.org/10.1046/j.1365-2214.2001.0190c.x 
Wiyani, N. A. (2019). Strategi Kemitraan Penyelenggaraan Parenting Bagi Orang Tua di Lembaga PAUD Kecamatan Bumiayu Kabupaten Brebes. Dimas: Jurnal Pemikiran Agama Untuk Pemberdayaan, 19(2), 143. https://doi.org/10.21580/dms.2019.192.4354

Wulandari, S., \& Afiatin, T. (2020). Positive Parenting Program to Improve Mother Efficacy in Parenting Teenagers. Jurnal Psikologi, 47(1), 30. https://doi.org/10.22146/jpsi.44971

Yeni Lestari, N. G. A. M. (2019). Program Parenting Untuk Menumbuhkan Kesadaran Pentingnya Keterlibatan Orang Tua di Paud. Pratama Widya : Jurnal Pendidikan Anak Usia Dini, 4(1), 8. https://doi.org/10.25078/pw.v4i1.1064 